\title{
A ESTRATÉGIA OPERATÓRIA UTILIZADA PELOS TRABALHADORES E O HIATO EXISTENTE ENTRE O TRABALHO PRESCRITO E O TRABALHO REAL
}

\section{STRATEGY OPERATÓRIA USE BY WORKERS IN HIATO EXISTING BETWEEN THE WORK GIVEN IN REAL WORK}

\author{
Andréa Cristina Trierweiller ${ }^{1}$; Beatriz Marcondes de Azevedo ${ }^{2}$; Vera Lucia Duarte do Valle \\ Pereira $^{3}$; Roberto Moraes Cruz ${ }^{4}$; Leila Amaral Gontijo ${ }^{5}$; Roberto Luis de Figueiredo dos \\ Santos Júnior ${ }^{6}$ \\ ${ }^{1}$ Universidade Federal de Santa Catarina (UFSC) - andreatri@gmail.com \\ ${ }^{2}$ Universidade Federal de Santa Catarina (UFSC) - biabizzy@uniplac.net \\ ${ }^{3}$ Universidade Federal de Santa Catarina (UFSC) - vpereira@deps.ufsc.br \\ ${ }^{4}$ Universidade Federal de Santa Catarina (UFSC) - rcruz@cfh.ufsc.br \\ ${ }^{5}$ Universidade Federal de Santa Catarina (UFSC) - leila@deps.ufsc.br \\ ${ }^{6}$ Universidade Federal de Santa Catarina (UFSC) - figueiredo@back.com.br
}

Resumo:

O presente artigo tem como objetivo sistematizar conhecimentos que permitam compreender as formas de elaboração das estratégias operatórias dos trabalhadores utilizadas para regular e manter o equilíbrio no circuito do trabalho. Diante das prescrições e das condições do trabalho, o trabalhador mobiliza uma série de processos cognitivos para elaborar a tarefa $e$ executar sua atividade, bem como para poder lidar com as variabilidades $e$ imprevisibilidades presentes no seu cotidiano laboral e assegurar a eficácia de suas ações. São as estratégias operatórias, resultantes de decisões que ocorrem nos diferentes níveis da organização que possibilitam as margens de regulação do trabalhador e conformam diferentes cargas de trabalho. A elaboração de tais estratégias depende, dentre outros fatores, do perfil individual do trabalhador, da sua experiência e competência profissional, de seu estado de saúde e da forma como o trabalho está organizado. A contribuição da ciência ergonômica está na criação de um alargamento da margem de manobra entre o prescrito e a atividade real de trabalho, de modo a eliminar, ou ao menos reduzir, a cisão entre as instâncias de planejamento e execução do trabalho. Para tanto, busca-se ampliar a possibilidade de regulação do trabalhador, conferindo-lhe uma maior autonomia e controle, tanto na execução das tarefas quanto na definição dos resultados esperados.

Palavras-chaves: estratégias operatórias, processo decisório e regulação 


\section{Introdução}

A Psicologia do Trabalho tem como objeto central de seus estudos o comportamento do homem em situação de trabalho. Para a Ergonomia, essa situação é descrita a partir dos principais elementos que a compõe, a saber: as exigências inerentes às tarefas e impostas direta ou indiretamente pela organização do trabalho; a atividade que é a própria execução do trabalho; os riscos potenciais e adicionais; os resultados conseguidos mediante a realização da atividade e traduzidos em desempenho dos trabalhadores e a carga de trabalho a que eles estão submetidos, cada vez que tentam manter o equilíbrio entre as exigências das tarefas e seus desempenhos profissionais e, que procuram controlar os efeitos dessa relação para si mesmos, como para os outros envolvidos no circuito do trabalho.

Ao realizar o seu trabalho, o trabalhador desenvolve uma série de estratégias operatórias que usualmente são caracterizadas pelo perfil individual, pela competência profissional, pelo seu estado de saúde e pela forma como o trabalho está organizado. Tais estratégias servem para lidar com os desequilíbrios e incompatibilidades existentes entre as diferentes lógicas (da produção, dos trabalhadores e dos usuários dos serviços e/ou produtos) e que se manifestam sob a forma de incidentes críticos, tais como: filas de espera, reclamações, erros, retrabalhos etc.

Dito de outro modo, as estratégias operatórias são recursos que os trabalhadores utilizam para gerir as variabilidades presentes em maior ou menor grau em qualquer situação de trabalho. Ou seja, são os modos de fazer e regular o trabalho e visam preservar as normas organizacionais para atingir o objetivo final proposto tanto pela organização, como pelo trabalhador e os outros membros ali presentes. De uma forma geral, diz-se que no processo de regulação das variabilidades presentes nos sistemas de trabalho, os trabalhadores produzem modos operatórios para cumprir os objetivos organizacionais e, em última instância, preservar sua saúde.

Com base no exposto, tem-se como objetivo desse artigo sistematizar conhecimentos que permitam compreender as formas de elaboração das estratégias operatórias dos trabalhadores utilizadas para regular e manter o equilíbrio no circuito do trabalho.

\section{Procedimentos metodológicos}

O presente artigo apresenta-se como uma revisão da literatura especializada e caracteriza-se pela sua natureza exploratória-descritiva. Primeiramente, foi realizada uma pesquisa bibliográfica em bases de dados, utilizando como descritores: "processo decisório", "estratégias operatórias" e "regulação". Dos artigos resultantes da busca, foram selecionados 
aqueles que demonstraram maior consistência com os objetivos desse trabalho e, então foi elaborada uma sistematização do conhecimento sobre o tema central do mesmo.

3. Contribuições da Ergonomia Cognitiva e Psicologia Cognitiva para o entendimento do trabalho real

A Ergonomia Cognitiva é uma especificidade da Ergonomia que se preocupa com o entendimento dos modelos mentais tanto pelo aspecto estrutural (procedimentos memorizados), quanto pelo aspecto processual (mudança das representações em função das situações).

O conceito de representação é descrito pela Psicologia Cognitiva como sendo o resultado de um processo mnemônico necessário para a codificação da informação, seu armazenamento e sua evocação e, principalmente para que o indivíduo possa compreender e agir diante de uma determinada situação. Teixeira (apud SILVINO, 1999) menciona as representações como sendo estados mentais que promovem um elo entre o ser humano e um dado contexto.

Conforme Abrahão, Silvino e Sarmet (2005), a contribuição da Ergonomia Cognitiva e Psicologia Cognitiva está justamente no fornecimento de subsídios teórico-metodológicos para investigar a maneira que o trabalhador gerencia o seu trabalho e as informações disponibilizadas para, assim, apreender a articulação que ele constrói e que conseqüentemente, o leva a realizar determinada ação.

De uma forma genérica, enfatiza-se a preocupação em compreender os processos cognitivos de buscar, interpretar, organizar, memorizar informações que subsidiem as tomadas de decisões relativas ao planejamento e execução das ações.

\subsection{A forma que o trabalho é concebido e executado}

O objetivo de compreender as estratégias operatórias utilizadas pelos trabalhadores requer a identificação do trabalho prescrito (tarefa), do trabalho real (atividade) e das condições de trabalho (exigências, cargas, riscos).

A tarefa é entendida como o trabalho prescrito a partir da concepção do cargo traçada pela organização e conseqüentemente, do perfil desejado do seu ocupante. Tais noções envolvem as atribuições que o trabalhador deve executar e como ele deve ser. Em outros termos, a tarefa é pré-existente à atividade e é resultante da concepção formal e informal de quem determina a execução do trabalho. 
Conforme Leplat (1986), a tarefa se distingue em prescrita e efetiva. Tarefa prescrita é a estabelecida pela organização do trabalho e imposta ao trabalhador, enquanto a tarefa efetiva é a tarefa já redefinida pelo indivíduo para possibilitar a sua execução, haja vista as particularidades do posto de trabalho e as especificidades de cada um.

Desse modo, para Ferreira e Freire (2000), a descrição da tarefa veicula explícita ou implicitamente um modelo idealizado de trabalhador e, por ser entendida por Guérin et all (2001) como também um conjunto de representações, requer do trabalhador uma dupla demanda: de elaboração e de execução da tarefa. Ou seja, essa variabilidade exige que o trabalhador mobilize seus recursos cognitivos para planejar e realizar o trabalho e está relacionada ao fato de que os responsáveis pelas prescrições não levam em consideração as diferenças entre os trabalhadores e também as imprevisibilidades inerentes a qualquer sistema de trabalho.

Guérin et all (2001) entendem que a atividade é o elo central que organiza e estrutura os elementos da situação de trabalho. "É uma resposta aos constrangimentos determinados exteriormente ao trabalhador, e ao mesmo tempo é capaz de transformá-los" (p.26). Esses constrangimentos são as exigências que, por sua vez, podem ser traduzidas como estímulos, informações que provocam desempenho. Tais exigências podem ser de natureza fisiológica, ambiental, sensorial, sensorial-motora e mental ou, resumidamente, de natureza física, cognitiva e psíquica. Segundo Cruz (2005), as exigências postas no plano físico, cognitivo e psíquico formulam desempenhos (faceta observável do comportamento) que viabilizam a demonstração das competências dos trabalhadores.

Ferreira (2002) chama a atenção para o "efeito bumerangue" do trabalho, pois o trabalhador, ao agir direta ou indiretamente (mediação instrumental) sobre o objeto (real ou simbólico), por meio da atividade, é, ao mesmo tempo metaforseado pelo resultado de suas ações, também, transforma o meio. O "efeito bumerangue" sofre influência das condições em que o trabalho é realizado, pois as exigências postas, as competências demonstradas, a carga de trabalho formulada e os riscos envolvidos irão impactar o trabalhador.

Cruz (2004) assinala que a partir da especificidade da exigência que a atividade requer do trabalhador é possível um entendimento do conceito de carga de trabalho. Leplat e Cuny (1977) partem do pressuposto de que ela é sempre resultado de uma interação e Cruz (2004, p. 236) corrobora afirmando que "carga de trabalho representa a diferença ou produto, regulado pelo trabalhador, entre as exigências sociotécnicas do trabalho e a condição de execução ou desempenho das tarefas". 
Para Djibo, Valléry e Lancry (2006), a carga de trabalho designa as conseqüências da execução da tarefa sobre o trabalhador, pois é ele quem desenvolve estratégias de adaptação para poder enfrentar fenômenos da carga. A partir dos pressupostos leplatianos, os autores assinalam que a tarefa propriamente dita e seus constrangimentos são reagrupados sob a denominação de exigências do trabalho.

Os mesmos autores enfatizam que os meios para regular os fenômenos de carga são oriundos essencialmente dos conhecimentos e do saber-fazer dos trabalhadores que, por sua vez, fornecem os recursos cognitivos que servirão para comparar as situações atuais com as passadas, permitindo assim a categorização dos problemas.

Wisner (1994) se mostra consoante com esses autores ao afirmar que para o trabalhador responder às exigências da atividade é necessário também controlar os efeitos de sua ação. O grau de sucesso ou fracasso do controle de tais efeitos depende, sobremaneira, das competências demonstradas pelo trabalhador durante a execução da atividade. Nesse sentido, diz-se que a análise da carga de trabalho se assenta na idéiao de que a mesma é um produto da relação entre condicionantes internas e externas ao trabalhador. Tal análise requer o levantamento dos elementos que contigenciam as possibilidades de ação e de regulação dos trabalhadores e que definem as exigências físicas, cognitivas e psíquicas do trabalho.

\subsection{A variabilidade dos trabalhadores e do sistema de trabalho}

A Ergonomia parte do pressuposto de que em qualquer situação de trabalho existe uma discrepância entre o que é prescrito e o que é realizado. Existe uma gama de variáveis que influenciam a ocorrência de tal fato e dentre elas, pode-se mencionar: a variabilidade dos trabalhadores, tanto em termos intra-individual como interindividual; a variabilidade dos sistemas de trabalho em relação às condições físico-ambientais (luz, ruído, calor) e instrumentais (material, tecnologia, equipamento); as lógicas contraditórias da produção e dos trabalhadores; as informações acessíveis para planejamento e execução do trabalho.

A variabilidade é assim um conceito importante em Ergonomia e é definida a partir de duas perspectivas: a da variação das condições de produção que são originadas das indeterminações e intercorrências inerentes ao mundo do trabalho e, a da variação dos trabalhadores que são advindas da susceptibilidade das dinâmicas interindividual (diferença entre os trabalhadores) e intra-individual (variação interna de cada trabalhador) (ABRAHÃO, 2000; FERREIRA, 2000; GUÉRIN et all 2001; PINHO, ABRAHÃO e FERREIRA, 2003). 
Conforme esses autores, a variabilidade humana impossibilita a prescrição e a realização de desempenhos iguais dos trabalhadores. Além disso, Fernandes et all (2002) chamam a atenção de que a lógica racional de produtividade não leva em conta o desgaste e as competências necessárias para o desempenho das tarefas prescritas.

As variações interindividuais estão relacionadas ao sexo, idade, personalidade, história pregressa, experiências e vivências dentro e fora do local de trabalho, e as variações intraindividuais, as quais são classificadas em curto, médio e longo prazos. São de curto prazo, quando verificadas, por exemplo, no decorrer da jornada de trabalho e influenciadas pelas exigências cotidianas, pelas mudanças impostas ao corpo, pelos ritmos circadianos e pelos acontecimentos extralaborais. Podem ser de médio prazo, verificadas ao longo de semanas e meses, influenciadas pelo desgaste físico, mental e psicológico do trabalhador, acumulado ao longo de curtos intervalos e produzindo uma sensação de cansaço ou fadiga crônica. São de longo prazo, se constatadas ao longo de anos e determinadas não só pelo envelhecimento biológico do trabalhador, mas, principalmente, pelos efeitos advindos das condições e organização do trabalho.

Ferreira (1997) denomina as variações intra-individuais de chrónostatus e assinala que se deve considerar o estado pessoal de cada trabalhador em função da variável tempo. Segundo o autor, essas variações repercutem no modo de agir de cada um, na sua conduta no trabalho em termos físicos (posturas, gestos, movimentos, deslocamentos), cognitivos (diagnóstico, planejamento e resolução de problemas) e afetivos (vivências de prazer/sofrimento e construção da identidade).

A presença da variabilidade e imprevisibilidade na situação de trabalho requer dos trabalhadores o investimento de suas inteligências na busca constante de um estado de equilíbrio. O seu conhecimento e o saber-fazer estão diretamente relacionados com os resultados de eficácia, conforto, segurança e saúde no trabalho.

\section{$3.3 \mathrm{O}$ agir organizacional}

Ao partir do pressuposto de que qualquer organização de trabalho está sujeita à variabilidade e à imprevisibilidade dos elementos que a configuram, é possível pensar a organização como um processo dinâmico que leva em consideração a ação coletiva, a cooperação e coordenação dos procedimentos prescritos e dos atos produtivos.

A referência ao agir organizacional é atribuída à Maggi (2006). Segundo ele, a abordagem ergonômica centra-se além de uma dupla abstração da situação de trabalho: a 
psicofisiológica do trabalhador individual e a taylorista da tarefa individual. Em outros termos, pode-se dizer que todo trabalho comporta uma dimensão coletiva e que cada tarefa está conectada com outras tarefas dispostas nos diferentes níveis da hierarquia organizacional.

Maggi (2006) assinala que as ações cooperativas precisam estar ordenadas para o alcance do resultado desejado, porém a coordenação pode ser contextual (intrínseca à ação) ou decidida anteriormente. Nesse caso, o autor está se referindo aos espaços de ação nãoprescritos e à possibilidade da coletividade influenciar as normas organizacionais no sentido de regular o processo de trabalho para seu cumprimento eficaz.

Outros dois conceitos presentes na teoria do agir organizacional são: autonomia e discricionariedade. A possibilidade de influenciar as normas e até mesmo modificá-las depende da capacidade dos trabalhadores de produzirem suas próprias regras e gerirem seus próprios processos de ação, ou seja, tem-se como pré-requisito a sua autonomia.

Em relação à discricionaridade, para Maggi (2006), essa indica os espaços de ação dentro de um processo regrado, onde o trabalhador é visto como um ser ativo, que precisa decidir e escolher a forma mais adequada de realização do trabalho, intervindo assim para integrar ou mudar as regras prescritas. Noutros termos, a discricionariedade é vista como o espaço da autonomia dentro do previsto que é utilizada para enfrentar a incerteza e a variabilidade das situações de trabalho.

Quando se pensa em autonomia dos trabalhadores e na possibilidade de se criar novas regras ou modificar as existentes está-se veiculando a idéia do agir organizacional. Assim, pode-se dizer que o trabalho é sempre "organizante" e ao mesmo tempo "organizado", pois os membros da organização assumem uma postura ativa que propicia um ordenamento construtivo e sempre mutável do processo de ações coletivas e, em última instância, toda ação organizacional pode ser compreendida como ação de regulação.

3.4 O processo de regulação do trabalho: planejamento e ação do trabalhador

A cognição é um recurso indispensável para operacionalizar as exigências das tarefas. É a partir do seu aparato cognitivo que o trabalhador planeja o que e como deve fazer (independente do seu grau de conscientização) e, como de fato, atua no trabalho. A elaboração e execução do trabalho estão assentadas no processo de apropriação, de reinterpretação do prescrito pela organização e das variabilidades dos trabalhadores e do sistema de trabalho. 
Conforme Pinho, Abrahão e Ferreira (2003), a utilização dos recursos cognitivos requer a construção de representações mentais adequadas do processo em que tais recursos se inscrevem e, via de regra, desempenha uma função de conhecimento (geralmente antecipador) dos objetos da realidade externa e sobre os quais a função de diagnóstico e de tomada de decisão é dirigida.

Nesse sentido, diz-se que o funcionamento cognitivo depende da experiência, conhecimentos, características do contexto sócio-técnico e dos meios de trabalho disponibilizados. A interação dessas variáveis produz impacto sobre as exigências cognitivas, podendo facilitar ou dificultar as estratégias operatórias apropriadas para responder aos imperativos da produção. O grau de facilidade ou de dificuldade pode ser investigado em função da complexidade existente no trabalho.

Conforme Abrahão, Silvino e Sarmet (2005), a análise dos processos subjetivos é importante, pois possibilita compreender como os trabalhadores identificam e dimensionam uma dada situação, que informações levam em consideração na perspectiva de planejar e executar suas ações. Em outras palavras, os autores se referem ao conceito de estratégia operatória, pois entendem tais processos na sua dimensão cognitiva, a partir dos processos de categorização, resolução de problemas e tomada de decisão que resultam em um modo operatório adotado pelo trabalhador.

A execução das ações é apenas a parte visível do comportamento dos trabalhadores, porém só é possível ter acesso à maneira de processar informações e transformá-las em desempenho práxico ou desempenho motor, mediante a verbalização dos próprios indivíduos. Silvino (1999, p.8) aponta para "a necessidade de extrapolar aspectos observáveis/comportamentais da atividade, no sentido de evocar o chamado trabalho mental".

O trabalho mental está diretamente relacionado com os recursos cognitivos do trabalhador que são mobilizados para fazer frente às exigências do sistema de trabalho. Graças ao seu processo cognitivo, os indivíduos elaboram uma representação da situação que estão vivenciando na organização e decidem ações mais apropriadas para atingir os objetivos individuais e coletivos presentes no cotidiano do trabalho.

Para a abordagem ergonômica, o conceito de representação para ação é utilizado para explicar como os trabalhadores constroem os problemas encontrados e como elaboram soluções apropriadas. Em outros termos, tal conceito se refere aos processos mentais ativos de tomada de consciência e de apropriação das situações nas quais os trabalhadores estão implicados e, ao mesmo tempo, são resultados de suas atividades. 
Weill-Fassina et all (apud Silvino, 1999) afirmam que as representações para a ação veiculam dois aspectos complementares: a) dimensão produto: manifesto sob a forma de conceitos, de saberes, aptidões e competências, crenças, sensações vivenciadas; b) dimensão do processo: expresso em termos da elaboração (assimilação e acomodação) de caráter finalístico por meio do qual o trabalhador constrói e estrutura seus conhecimentos para interagir com o meio.

Aos processos de assimilação e acomodação está subjacente a idéia de que a ação do trabalhador permite a reestruturação das representações, fornece novos elementos e situações que enriquecem o conhecimento internalizado pelo trabalhador. Para Teiger (apud Silvino, 1999), três tipos de processos cognitivos participam da elaboração de uma representação para ação: a) memorização e evocação de conhecimentos adquiridos em diferentes contextos; b) esquematização e simbolização dos saberes adquiridos em conjunto com as informações atuais, que permitem o enriquecimento das representações em memória e; c) antecipação de possíveis transformações da situação e abstração das regras que atuam nessa mudança.

O conceito de representação na ação foi formulado para se referir às representações criadas para alcançar um objetivo, expresso na forma de uma ação. Conforme Teiger (apud Abrahão, Silvino e Sarmet, 2005), as representações para a ação são vistas como um conjunto de crenças, conhecimentos e habilidades, estruturado pela experiência do trabalhador.

A concepção formal da tarefa dá margens para generalização, superficialidade e ambigüidade, pois não considera o hiato existente entre o prescrito e o real. A gestão das informações selecionadas e tratadas pelo trabalhador visa alcançar os objetivos previamente estabelecidos e responder às exigências das tarefas. As representações que ele constrói para e na ação constituem uma ferramenta cognitiva imprescindível para garantir a qualidade final do trabalho, pois são os constantes reajustes que o ajuda a lidar com as variabilidades das situações de uma maneira mais eficaz.

\subsection{As estratégias operatórias com fins regulatórios}

As estratégias operatórias são ditas regulatórias na medida em que são elaboradas individualmente ou coletivamente para administrar a distância entre a atividade real e a prescrita na tarefa, de modo a equilibrar as variabilidades e imprevisibilidades da situação de trabalho e minimizar o custo da inadequação da prescrição no desempenho da atividade.

Terssac e Maggi (apud Ferreira, 2002) afirmam que as regulações permitem ao trabalhador gerir as variações das condições internas e externas da atividade e, de outro lado, 
para dar conta dos efeitos da atividade. Leplat $(1986 ; 2006)$ dá ênfase à idéia de que a definição de regulação implica sempre a presença de uma relação de interação entre elementos instáveis e que a resultante do funcionamento do sistema não depende somente da ação do trabalhador, mas também das condições das quais ele não tem controle direto.

Guérin et all (2001) corroboram afirmando que o trabalhador utiliza os meios de que dispõe, levando em conta seu estado de saúde, seus conhecimentos, desenvolvendo um modo operatório peculiar de agir nas situações de trabalho. Assim, para esses autores, a estratégia de regulação é um processo multideterminado por fatores de natureza distinta, a saber: interação do trabalhador com a tarefa prescrita (que veicula uma carga de trabalho específica com suas exigências físicas, cognitivas e afetivas); condições pessoais do trabalhador (estado de saúde, objetivos pessoais e experiência profissional); meios disponibilizados (materiais, instrumentais e tecnológicos); condições ambientais (espaço, luminosidade, temperatura, ruído) e mecanismos de retroalimentação de dois vetores da atividade: performance (eficiência e eficácia quanto aos objetivos estabelecidos) e bem-estar (condição de saúde enquanto estado em construção que abarca o sentir-se bem física, psicológica e socialmente).

Compreende-se, assim, que diante desse conjunto de variáveis, o trabalhador busca estruturar o programado ao antecipar as tarefas e executar o planejado ao operacionalizar o prescrito. Noulin (apud Ferreira e Barros, 2003) chama a atenção de que o homem que trabalha não é um mero executante, mas um operador no sentido de que ele faz a gestão das exigências, não se submetendo passivamente a elas. Ele aprende agindo, adapta o seu comportamento às variações, tanto de seu estado interno quanto dos elementos da situação. Ele decide sobre as formas mais adequadas de agir, inventa "truques", desenvolve habilidades para assegurar sua eficácia no trabalho.

A função regulatória é utilizada para que o trabalhador consiga responder às exigências de naturezas distintas e construir representações para e na ação compensando e/ou prevenindo os disfuncionamentos, buscando alcançar os objetivos estabelecidos por ele, pela organização e pelo grupo de trabalho e assim, minimizar o desgaste e o custo humano do trabalho.

\section{Considerações finais}

Os subsídios teórico-metodológicos oriundos da Psicologia do Trabalho, Ergonomia, Ergonomia Cognitiva e Psicologia Cognitiva permitem a compreensão de como o trabalhador realiza suas atribuições a partir das exigências e condições sócio-técnicas do sistema de 
trabalho. Independentemente da natureza do trabalho, qualquer conduta do trabalhador mobiliza e aciona uma série de processos que compõe seu aparato cognitivo.

$\mathrm{Na}$ situação de trabalho estão condensadas as relações recíprocas entre os processos ambientais, tecnológicos e psicossociais. Os trabalhadores, a partir da prescrição de suas tarefas, planejam suas operações e, com base, nos meios disponíveis, realizam a atividade de trabalho, em condições pré-determinadas e de um modo particular, o "modo operatório".

Em outras palavras, a prescrição das tarefas é imposta ao trabalhador, autorizando-o a desempenhar sua atividade que é a própria ação de fazer. Entre as tarefas prescritas pela organização de trabalho e a atividade realmente executada está a chamada "margem de manobra", que permite aos trabalhadores reordenar as condições da própria execução e alterar o modo operatório para outro mais favorável à sua saúde.

A partir do pressuposto de que o trabalho molda e é moldado pela situação de trabalho, entende-se que ao tomar contato com as prescrições organizacionais o trabalhador precisa primeiramente planejar suas ações para depois executá-las. A gestão das informações indispensáveis para que tais processos aconteçam é realizada mediante a construção de representações para e na ação.

Tais representações fazem parte da estratégia operatória dos trabalhadores, ou seja, de um modo de operar nas situações de trabalho de forma individual e coletiva para dar conta do cumprimento dos objetivos da produção, bem como regular e controlar os desequilíbrios existentes entre as exigências do sistema de trabalho e os desempenhos dos trabalhadores.

A situação de trabalho está permeada de variabilidades e imprevistos fazendo com que exista diferenças, em maior ou menor grau, entre o trabalho prescrito e o trabalho real. São as estratégias operatórias elaboradas pelos trabalhadores que os ajudarão a lidar com tais variabilidades e, conforme sua margem de autonomia, suas experiências, habilidades e competências conseguirão ser mais ou menos eficazes no controle dos efeitos da discrepância entre o prescrito e o real e na minimização do desgaste e do custo humano inerentes ao meio organizacional.

As ciências ergonômicas e psicológicas fornecem subsídios teórico-metodológicos para que o analista do trabalho possa propor alternativas que visem o incremento da margem de manobra, de modo que seja assegurada aos trabalhadores a possibilidade de regular seu próprio trabalho. Ou seja, que o trabalhador possa agir no sentido de alterar os meios e os objetivos na atividade de trabalho, preservando sua integridade e possibilitando a sua satisfação. Tais alternativas serão acionadas a partir do momento em que os trabalhadores 
sejam implicados nessa transformação, sendo reposicionados como pensadores, como sujeitos ao mesmo tempo da concepção e da execução do trabalho.

\section{Abstract}

This article aims to systematize knowledge to understand the ways of drawing up the strategies operative of the workers used to regulate and maintain a balance in the circuit of work. Due to the requirements and conditions of work, the worker mobilizes a series of cognitive processes to develop the task and perform your activity, as well as to deal with the variability in capricious present in your daily work and ensure the effectiveness of their actions. They are the operative strategies, resulting from decisions that occur at different levels of the organization that enable the margins of regulation of the worker and make different workloads. The development of these strategies depends, among other factors, the individual profile of the worker, their experience and professional competence of their state of health and how the work is organized. The contribution of science ergonomic is the creation of an enlargement of room for manoeuvre between the prescribed and actual activity of work, in order to eliminate, or at least reduce, the division between the planning and execution of the work. Thus, it is seeking to expand the possibility of regulating worker, giving it greater autonomy and control, both in the implementation of the tasks on the definition of the expected results.

Keywords: operative strategies, decision-making process and regulation

\section{Referências}

ABRAHÃO, J. I. Reestruturação produtiva e variabilidade do trabalho: uma abordagem da ergonomia. Psicologia: Teoria e Pesquisa, 16 (1), p.49-54, jun-abr, 2000.

ABRAHÃO, J. I.; TORRES, C. C. Entre a organização do trabalho e o sofrimento: o papel de mediação da atividade. Revista Produção, 14 (3), p. 67-76, set/dez, 2004.

CORDEIRO, V. R. V. Atividade de atendimento ao público, treinamento e custo humano do trabalho: o caso dos gerentes de contas de uma instituição bancária. Dissertação de Mestrado em Psicologia. UNB, 2005.

CRUZ, R. M. Apontamentos de aulas da disciplina psicologia do trabalho. Programa de Pós-Graduação em Engenharia da Produção. Universidade Federal de Santa Catarina, Florianópolis, 2005.

CRUZ, R. M. Distúrbios musculoesqueléticos, processos de trabalho e cultura organizacional. In: TAMAYO, A. et al. Cultura e saúde nas organizações. Porto Alegre: Artmed, 2004. 
DJIBO, S.; VALLÉRY, G; LANCRY, A. Charge mentale et régulation de systèmes complexes: approche subjective des agentes de régulation du métro parisien. activités, 3 (1), p.117-139, 2006. Disponível em <www.activites.org/v3n1/djibo.pdf> Acesso em 9 de maio de 2006.

DINIZ, E. P. H; ASSUNÇÃO, A. A.; LIMA, F. P. A. Prevenção de acidentes: o reconhecimento das estratégias operatórias dos motociclistas profissionais como base para a negociação de acordo coletivo. Ciência \& Saúde Coletiva, 10 (4), p. 905-916, 2005.

FERNANDES, S. R. P.; DI PACE, D. M. T; PASSOS, M. F. D. Organização e condições de trabalho em telemarketing: repercussões na saúde psíquica dos trabalhadores. In: JACQUES, M; CODO, W. (Org). Saúde mental e trabalho: leituras. Petrópolis: Vozes, 2002.

FERREIRA, M. C. Atividade, categoria central na conceituação de trabalho em ergonomia. Laboratório de Ergonomia. Universidade de Brasília, 1997.

FERREIRA, M. C. O sujeito forja o ambiente, o ambiente "forja" o sujeito: inter-relação indivíduo-ambiente em ergonomia da atividade. Laboratório de Ergonomia. Universidade de Brasília, 2002.

FERREIRA, M. C. Serviço de atendimento ao público: o que é? Como analisá-lo? Esboço de uma abordagem teórico-metodológica em ergonomia. Revista Multitemas, 16, p. 128-144, 2000 .

FERREIRA, M. C.; BARROS, P. C. R. (In) Compatibilidade do trabalho prescritotrabalho real e vivências de prazer-sofrimento dos trabalhadores: um diálogo entre a ergonomia da atividade e a psicodinâmica do trabalho. Alethéia, 2003.

FERREIRA, M. C; FREIRE, O. N. A empresa treina, mas na prática é outra coisa: carga de trabalho e rotatividade na função de frentista. Laboratório de Ergonomia. Universidade de Brasília, 2000.

GUÉRIN, F. et all. Compreender o trabalho para transformá-lo: a prática da ergonomia. São Paulo: Editora Edgard Blucher Ltda, 2001.

LEPLAT, J. e CUNY, X. Introdução à psicologia do trabalho. Lisboa: Fundação Calouste Gulbenkian, 1977.

LEPLAT, J. L'analyse psychologique du travail. Revue De Psychologie Appliqueé, 31 (1), p.9-27, 1986.

LEPLAT, J. La notion de régulation dans l'analyse de l'activité. Pistes 8(1), mai, 2006. Disponível em <www.pistes.uquam.ca/v8n1/articles/v8n1a7.htm $>$ Acesso em 2 de maio de 2006.

MAGGI, B. Do agir organizacional: um ponto de vista sobre o trabalho, o bem-estar, a aprendizagem. São Paulo: Edgard Blucher, 2006.

PINHO, D. L. M.; ABRAHÃO, J. I; FERREIRA, M. C. As estratégias operatórias e a gestão da informação no trabalho de enfermagem, no contexto hospitalar. Rev. Latino-Am Enfermagem, 11 (2), p. 168-176, 2003. 
RASIA, D; FERREIRA, M. C. Serviço de teleatendimento e desconforto corporal: aspectos físicos do custo humano no trabalho de teleatendimento. Dissertação de Mestrado em Psicologia. UNB, 2003.

SILVINO, A. M. D. A análise ergonômica do trabalho como suporte à formação profissional: a articulação entre estratégia operatória e expertise. Dissertação de Mestrado em Psicologia. UNB, 1999.

WISNER, A. Inteligência no trabalho: textos selecionados de ergonomia. São Paulo: Fundacentro, 1994.

\section{Dados dos autores}

Nome completo: Andréa Cristina Trierweiller

Filiação institucional: Universidade Federal de Santa Catarina - UFSC

Departamento:

Função ou cargo ocupado:

Endereço completo para correspondência: Rod SC 401 - Km1, n.407, Itacorubi, Florianópolis -SC, Brasil, CEP: 88030-000:

Telefones para contato: (48) $3202-6000$

e-mail: andreatri@gmail.com

Nome completo: Beatriz Marcondes de Azevedo

Filiação institucional: Universidade Federal de Santa Catarina - UFSC

Departamento:

Função ou cargo ocupado:

Endereço completo para correspondência (rua, número, bairro, cidade, estado, país, CEP):

Telefones para contato:

e-mail: biabizzy@uniplac.net

Nome completo: Vera Lucia Duarte do Valle Pereira

Filiação institucional: Universidade Federal de Santa Catarina - UFSC

Departamento:

Função ou cargo ocupado:

Endereço completo para correspondência (rua, número, bairro, cidade, estado, país, CEP):

Telefones para contato:

e-mail: vpereira@deps.ufsc.br 
Nome completo: Roberto Moraes Cruz

Filiação institucional: Universidade Federal de Santa Catarina - UFSC

Departamento:

Função ou cargo ocupado:

Endereço completo para correspondência (rua, número, bairro, cidade, estado, país, CEP):

Telefones para contato:

e-mail:rcruz@cfh.ufsc.br

Nome completo: Leila Amaral Gontijo

Filiação institucional: Universidade Federal de Santa Catarina - UFSC

Departamento:

Função ou cargo ocupado:

Endereço completo para correspondência (rua, número, bairro, cidade, estado, país, CEP):

Telefones para contato:

e-mail: leila@deps.ufsc.br

Nome completo: Roberto Luis de Figueiredo dos Santos Júnior

Filiação institucional: Universidade Federal de Santa Catarina - UFSC

Departamento:

Função ou cargo ocupado:

Endereço completo para correspondência (rua, número, bairro, cidade, estado, país, CEP):

Telefones para contato:

e-mail: figueiredo@back.com.br

Recebido para publicação em: 01/02/2008

Aceito para publicação em: 07/03/2008 